\title{
Slurry Erosive Wear Behavior of Plasma Sprayed Inconel-718 Coatings on Al6061 Alloy
}

\author{
C.S. Ramesh $^{1 *}$, Suresh Kumar ${ }^{2}$, D.S. Devaraj ${ }^{1}$, R. Keshavamurthy ${ }^{1}$ \\ ${ }^{1}$ Department of Mechanical Engineering, PES Institute of Technology, Bangalore, Karnataka, \\ India \\ ${ }^{2}$ Department of Mechanical Engineering, SBMJCE, Ramanagaram District., Karnataka, India \\ * Corresponding Author: csr_gce@yahoo.co.in
}

\begin{abstract}
Plasma Sprayed coatings provide protection against corrosion, erosion and wear. Inconel- 718 is a metallic coating which has good wear and erosion resistance. This is plasma sprayed on to Al6061 substrate and then subjected to slurry erosive wear tests. It is observed that the slurry wear rates of Al6061 decreased on coating the substrate material with Inconel- 718.
\end{abstract}

Keywords: Plasma spray, Inconel- 718, Al6061, Erosion.

\section{INTRODUCTION}

Out of many surface modification techniques, plasma spraying stands out as one of the most versatile and technologically sophisticated thermal spraying technique [10]. Plasma spraying is gaining extensive attention in the research fraternity as it has the advantage of applying coatings using different materials such as ceramic, metallic and composite coatings with possibility of controlling the thickness from few microns to few millimeters. Thus produced coatings improve hardness and hence reduce wear.

Al6061 has found many applications in the field of aeronautics, automobiles and other fabrication processes due to its high strength to weight ratio and excellent formability and corrosion resistance. However, its wear resistance is poor. Hence, an attempt has been made in the present work to develop metallic coatings using Inconel-718 to overcome the above limitations. 
In the recent past, many studies have been reported in the literature on wear behavior of different coatings on different substrates produced by plasma spray technique. Chang-Jiu Li etal [1] have reported that the erosion of plasma-sprayed ceramic coating was inversely proportional to the mean lamellar bonding ratio. The erosion resistance of a thermally sprayed ceramic coating was controlled by the fracture toughness of the coatings. Da-Wei Zhang et al [2] have concluded that the erosive-corrosive wear rate of stainless steel substrate reduced by about $50 \%$ by laser-clad $\mathrm{Ni}-\mathrm{Cr}_{3} \mathrm{C}_{2}$ composite coating in acidic slurry of quartz sand. Diana Lopez et al [3] have reported the formation of cracks in the coating and plastic deformation in both the substrate and the coating, especially when the mean impact velocity exceeded a critical value between 6.9 and 8.6 $\mathrm{ms}^{-1}$. Hoppel et al [4] have coated different combinations of $\mathrm{Co} / \mathrm{WC}$ and $\mathrm{NiCr} / \mathrm{Cr}_{3} \mathrm{C}_{2}$ on different alloy substrates of $\mathrm{Ni}, \mathrm{Cr}$ and $\mathrm{Mo}$ combinations and have reported that the slurry erosive wear resistance of coated specimens are greater in comparison to the un-coated substrate. Wang et al [5] have concluded that the slurry erosion resistances of the $\mathrm{Ti} \mathrm{N}$ coatings were significantly higher than that of the uncoated mild steel and the AISI 304 stainless steel. They have observed that increase of particle erosion speed had no significant effect on the erosion of coatings. Jari Knuuttila et al [6] have reported that aluminum phosphate sealing gives the best improvement in slurry erosive wear resistance of alumina and chromia coatings when the wear is dominated by brittle fracture and the contact conditions are relatively rough. However, if tribochemical wear is encountered, sealing with aluminum phosphate has no effect.

Rutherford et al [7] have reported that use of polymer films on steels have resulted in improved slurry erosion wear resistance. Hadad et.al [8] have reported that $\mathrm{WC}-\mathrm{Cr}-\mathrm{Co}$ coatings deposited by thermal spray methods on steel substrate exhibited improvement in slurry erosive wear resistance. Abou El-Khair et al [9] have concluded that use of nickel coating on aluminum based composites by electrochemical deposition have exhibited high hardness, corrosion and wear resistance against slurry erosion. However, meager information is available as regards the study on Inconel coatings on A16061 substrate.

In the light of the above, this work focuses on development of plasma sprayed Inconel-718 coatings on A16061 substrate and to investigate the slurry erosive wear behavior of the developed coatings.

\section{EXPERIMENTAL DETAILS}

\subsection{Materials}

\subsubsection{Coating material: Inconel-718}

Inconel-718 is chosen as the coating material. It is nickel based super alloy having excellent wear and corrosion resistance coupled with high strength at ambient temperature. This alloy finds 
variety of applications like gas turbines, jet engines, steam generators, fission and fusion reactor structures. Table 1 gives the chemical composition of Inconel-718 used in the present work. The size of the particles of Inconel-718 alloy powder used ranged between 20 to $50 \mu \mathrm{m}$.

Table 1: Chemical composition of Inconel -718

\begin{tabular}{|c|c|}
\hline Element & Weight \% \\
\hline Carbon & 0.08 \\
\hline Manganese & 0.35 \\
\hline Silicon & 0.35 \\
\hline Phosphorus & 0.015 \\
\hline Sulfur & 0.015 \\
\hline Nickel + Cobalt & 55.0 \\
\hline Chromium & 21.0 \\
\hline Cobalt & 1.00 \\
\hline Aluminum & 0.80 \\
\hline Molybdenum & 3.30 \\
\hline Titanium & 1.15 \\
\hline Boron & 0.006 \\
\hline Copper & 0.15 \\
\hline Cb + Ta & 5.50 \\
\hline Iron & Balance \\
\hline
\end{tabular}

\subsubsection{Substrate material: Al6061 alloy}

Al6061 is selected as substrate material. Table 2 gives the chemical composition of Al6061 substrate used in the present work. Al6061 plates were cut to produce specimen of size $22 \mathrm{~mm} \times 25 \mathrm{~mm} \times 8 \mathrm{~mm}$. These samples were thoroughly cleaned using acetone followed by grit blasting.

Table 2: Chemical composition of Al6061 (Major elements)

\begin{tabular}{|cc|}
\hline Element & Weight \% \\
$\mathrm{Al}$ & 97.9 \\
$\mathrm{Si}$ & 0.60 \\
$\mathrm{Cu}$ & 0.28 \\
$\mathrm{Mg}$ & 1.0 \\
$\mathrm{Cr}$ & 0.20 \\
\hline
\end{tabular}




\subsection{Coating Procedure}

Air Plasma Spray (APS) coating was carried out at M/S Metallizing Equipment Company Pvt. Ltd. Jodhpur, India. SG-100 torch mounted on a computer controlled KUGA robot is used for plasma spraying Inconel-718 alloy powder on grit blasted Al6061substrate. Hydrogen and argon gases are used as inert gases during the coating process. Table 3 gives the plasma spray parameters adopted in the present work to develop coatings of thicknesses 200 and $250 \mu \mathrm{m}$. A constant stand off distance of 5" was adopted.

Table 3: Plasma spray parameters

$\begin{array}{ll}\text { Voltage } & 40 \text { volts } \\ \text { Current } & 800 \mathrm{amps} \\ \text { Primary Inert gas - Argon gas } & 40 \mathrm{LPM} \\ \text { Secondary Inert- hydrogen } & 0.4 \mathrm{LPM} \\ \text { Carrier gas - Argon gas } & 2 \mathrm{LPM} \\ \text { Power } & 32 \mathrm{KW} \\ \text { INCONEL718 powder } & 100 \mathrm{gm} / \mathrm{min} \\ \text { Powder feed rate } & 33 \mathrm{grams} / \mathrm{min}\end{array}$

\subsection{Slurry Erosion Test}

Wear of Inconel-718 coated on Al6061 specimens were studied using standard slurry erosive wear tester as shown in Fig.1. Prior to the tests, the samples were thoroughly cleaned with acetone and its initial weight was measured using an electronic balance of accuracy $0.01 \mathrm{mg}$. The specimens were then fixed to the spindle of the tester with the samples fully immersed in slurry media of $3.5 \% \mathrm{NaCl}$ and silica sand of particular grit size. Tests were conducted for various slurry concentrations and coating thicknesses. The particle size of sand particles was $600 \mu \mathrm{m}$ while the speed of rotation and time period were maintained at 500rpm and $15 \mathrm{hrs}$ respectively. After the test, the specimens were cleaned with acetone and its weight is measured to assess the slurry erosion wear loss of the samples. 


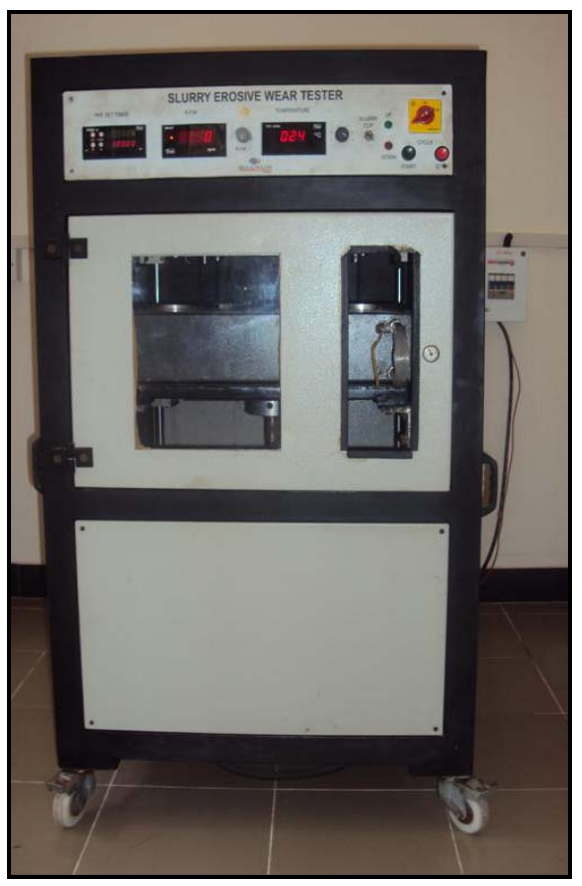

Fig. 1 Photograph of slurry erosion wear tester

\section{RESULTS AND DISCUSSIONS}

\subsection{Microstructure}

Fig. 2 shows the SEM of cross section of the coatings. Further, coating thickness of $200 \mu \mathrm{m}$ can be observed. A good bond between the coating and the substrate do exist indicating that the adopted coating process parameters are optimal. It is observed that there exist several layers of deformed particles with typical lamellar structure. No visible cracks are being observed in both the coating and the substrate. A dense and uniform coating can be observed.

Fig. 3a shows the SEM photograph of uncoated Al6061 substrate. The rough surfaces observed on the substrate is due to grit blasting. Fig.3b shows the SEM of the coated specimen. The surface morphology of the coatings clearly indicates that the obtained coating is uniform and dense. 


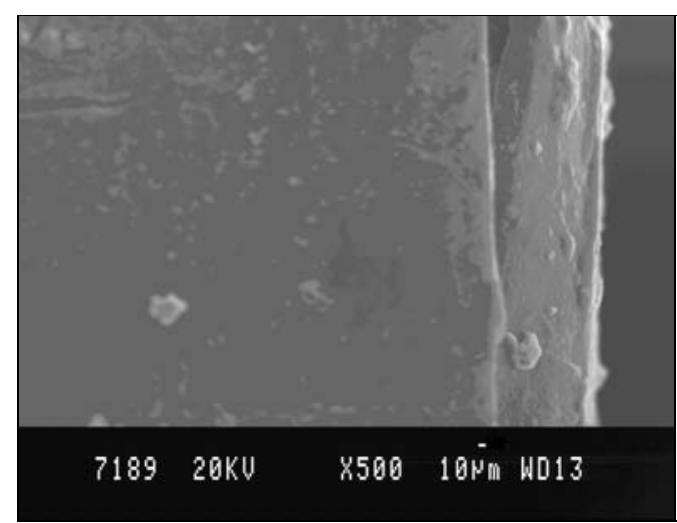

Fig. 2 SEM of cross sectional micrograph of Inconel-718 on Al6061 alloy

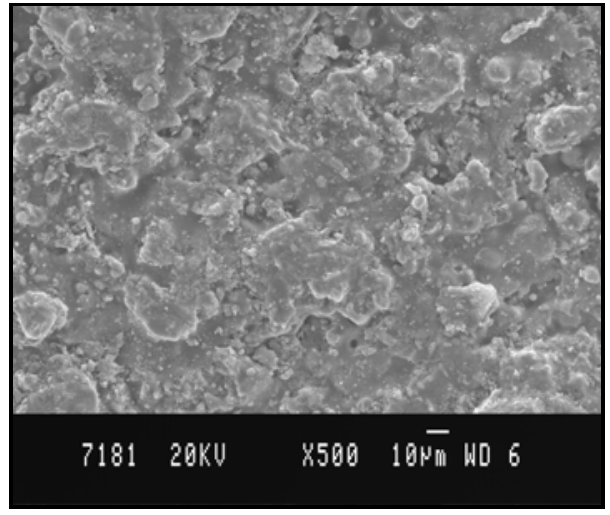

(a) Grit blast Al6061 substrate

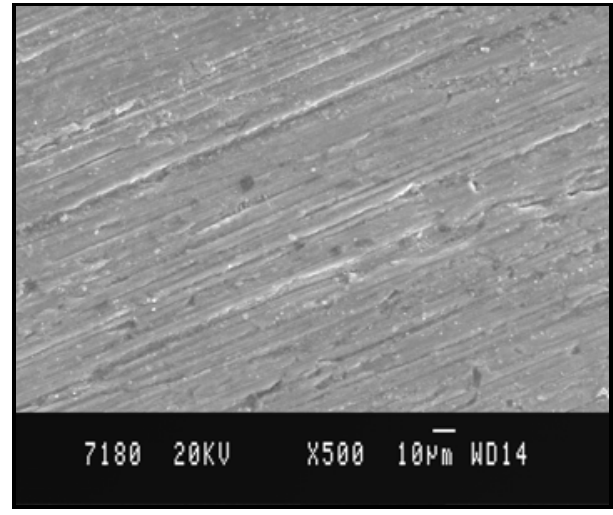

(b) Inconel 718 coatings on Al6061 substrate

Fig. 3(a-b) SEM of uncoated and coated Al6061 alloy surfaces

\subsection{Slurry Erosion Test}

\subsubsection{Effect of slurry concentration}

Fig. 4 shows the effect of slurry concentration on erosive wear of uncoated and Inconel-718 coated A16061. It can be observed that the mass loss of uncoated Al6061increases steeply with increase in slurry concentration. However, a marginal increase in mass loss is observed in case of the developed coatings. An excessive material removal is observed in case of uncoated Al6061samples at all the slurry concentrations. This can be attributed mainly to its lower hardness and poor erosion resistance. Further, increased coating thickness results in reduced slurry erosive wear loss for all the slurry concentration studied.

The improvement in the slurry erosion resistance of the coatings can be attributed to the following reasons. 




Fig.4 Effect of slurry concentration on slurry erosive wear of Inconel-718 coatings

Increase in hardness and strength of Inconel-718, higher toughness of the coatings, excellent corrosion resistance of Inconel 718 as it contains higher proportions of alloying elements such as nickel, cobalt and chromium. These alloying elements favors the formation of stable oxide films which are corrosion protective in nature thereby enhancing the slurry erosion resistance of the coatings. However, the increased mass loss with increase in slurry concentration of all the studied materials can be attributed to fact that, increased abrasive particle concentration in the slurry enhances the probability of more impingements on the surfaces leading to increased deterioration of material from its surfaces.

\subsubsection{Effect of coating thickness}

Fig. 5 shows slurry erosive wear loss of uncoated and Inconel-718 coated Al6061 with increase in coating thickness for a given slurry concentration. It can be observed increase in the coating thickness results in better slurry erosion resistance of the coatings. This can be mainly attributed to the higher extent of corrosion protection of the surfaces with increased coating thickness. Increased coating thickness results in porosity reduction which is a major factor affecting corrosion. Presence of porosity leads to higher extent of localized pitting which accelerates the material removal process during slurry erosion tests where the primary mechanism of material removal is corrosion. 


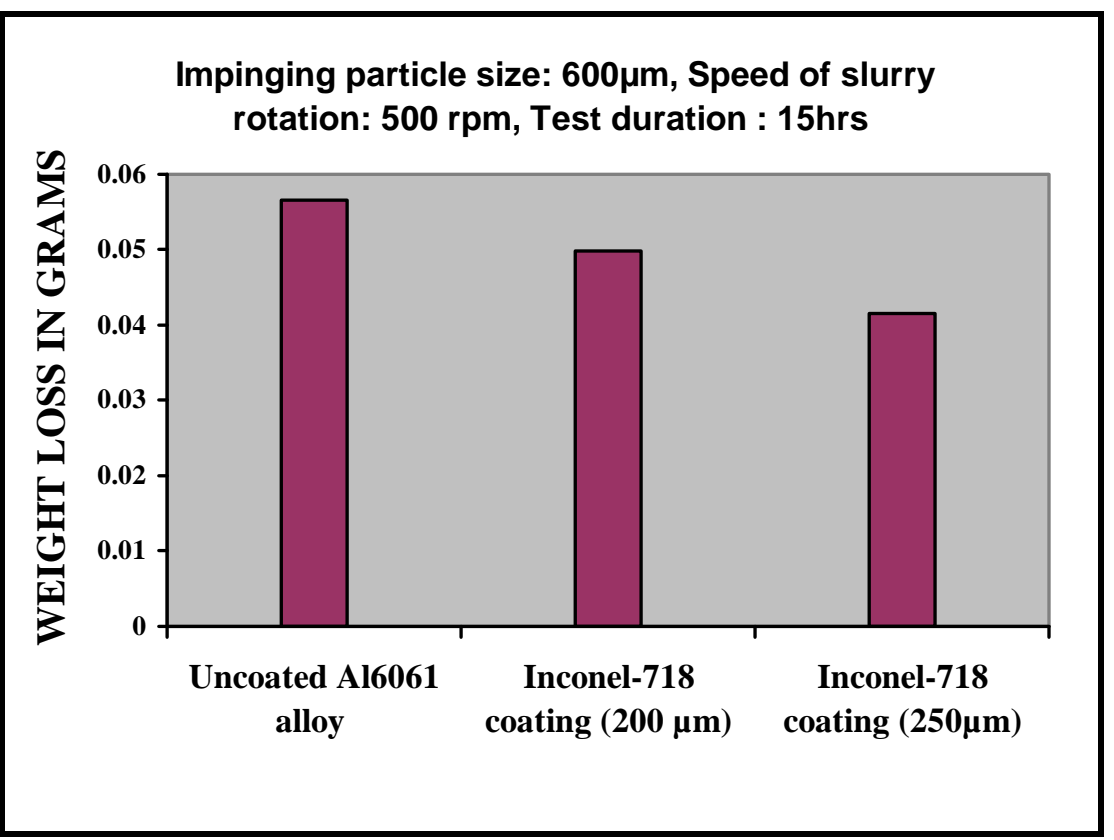

Fig. 5: Effect of coating thickness on slurry wear loss at slurry concentration of 100 g/litre

\section{CONCLUSIONS}

Plasma sprayed Inconel 718 coatings have significantly improved the slurry erosion resistance of Al6061 substrate in $3.5 \% \mathrm{NaCl}$ sand slurry.

\section{REFERENCES}

1. Chang-Jiu Li , Guan-Jun Yang, Akira Ohmori, "Relationship between particle erosion and lamellar microstructure for plasma-sprayed alumina coatings", Wear 260 (2006) 1166-1172.

2. Da-Wei Zhang, T.C. Lei , "The microstructure and erosive-corrosive wear performance of laser-clad Ni-Cr $\mathrm{C}_{2}$ composite coating”, Wear 255 (2003) 129-133.

3. Diana Lopez, Carlos S'anchez, Alejandro Toro, "Corrosion-erosion behavior of TiN-coated stainless steels in aqueous slurries”, Wear 258 (2005) 684-692.

4. H.W. Hoppel, H. Mughrabi, H.-G. Sockel, S. Schmidt, G. Vetter, "Hydroabrasive wear behaviour and damage mechanisms of different hard coatings", Wear 225-229 (1999) 10881099.

5. H.W. Wang, M.M. Stack, "Erosion of PVD TiN coatings under simultaneous corrosion in sodium carbonate/bicarbonate buVer slurries containing alumina particles", Surface and Coatings Technology 106 (1998) 1-7.

6. Jari Knuuttila, Samppa Ahmaniemi, Tapio Mantyla, "Wet abrasion and slurry erosion resistance of thermally sprayed oxide coatings", Wear 232 (1999) 207-212. 
7. K.L. Rutherford , R.I. Trezona , A.C. Ramarruuthy , I.M. Hutchings, "The abrasive and erosive wear of polymeric paint films", Wear 203-204 ( 1997) 325-334.

8. M. Hadad, R. Hitzek, P. Buergler, L. Rohr, S. Siegmann, "Wear performance of sandwich structured WC-Co-Cr thermally sprayed coatings using different intermediate layers", Wear 263 (2007) 691-699.

9. M.T. Abou El-Khair, A. Abdel Aal, "Erosion-corrosion and surface protection of A356 $\mathrm{Al} / \mathrm{ZrO}_{2}$ composites produced by vortex and squeeze casting", Materials Science and Engineering A 454-455 (2007) 156-163.

10. S. Das, S. Ghosh, A. Pandit, T. K. Bandyopadhyay, A. B. Chattopadhyay, K. Das, "Processing and characterization of plasma sprayed zirconia-alumina-mullite composite coating on a mild-steel substrate", Journal of Materials Science 40 (2005) 5087-5089. 